Liyanage K., Tennakoon W.D.N.S.M., Wayamba Journal of Management 11 (2)

\title{
Factors Affecting Generation Y's Consumer Conformity Behaviour in Social Networking Sites; with Special Reference to Retail Fashion Industry in Colombo District, Sri Lanka
}

\author{
K. Liyanage ${ }^{1}$ \& W.D.N.S.M. Tennakoon ${ }^{2}$ \\ 1,2 Department of Business Management \\ Faculty of Business Studies \& Finance \\ Wayamba University of Sri Lanka \\ Kuliyapitiya \\ SRI LANKA \\ $\underline{\text { kaushiliyanagemc@gmail.com }{ }^{1}}$ tennakoon@wyb.ac.lk ${ }^{2}$
}

\begin{abstract}
The development of social networking platforms on the internet tremendously impacts to the facilitation of global social interconnections. Consumers are influenced by a variety of social networks in which Facebook plays a major role. Considering the rising Gen Y's Social Networking Sites (SNS) involvement, modern fashion brands consider Facebook as a business take-off tool. Thus, the objective of this study was to investigate factors influencing Gen $\mathrm{Y}$ consumer conformity behaviour in SNS in the context of the retail fashion industry in Sri Lanka. A deductive, cross-sectional research inquiry was carried out using five independent variables, which equipped a field survey of $(\mathrm{N}=214)$ respondents belonging to Gen Y from the Colombo District, Sri Lanka. Research instrument of 32 items used in which the responses were ranked based on a seven-point Likert scale. Findings carry practical implications in focusing on the influential factors on Gen Y consumer conformity behaviour in SNS in driving retail fashion industry.
\end{abstract}

Keywords: - Consumer conformity, Generation ' $Y$ ', Retail fashion industry, Social Networking Sites (SNS)

\section{INTRODUCTION}

No denying is to be placed that globalization, internet and networking in the virtual spaces have changed the whole concept of a consumer. The modern technology has brought the consumer markets more collaborative, dynamic and tremendously interconnected over the years, that marketers and brand personnel had to initiate on researching about the new consumer behaviour in its new angle. As evidenced by many scholarly work consumer behaviour is considered as a lot more challenging field of study (Martinez-Ruiz \& Moser, 2019) in the present context. In identifying and analysing the modern perspective of consumer behaviour as stated by (Schiffman, et al., 2010) a firm's marketing efforts and the sociocultural environment plays salient roles. The socio-cultural environment has led to the creation of an inseparable relationship with the consumer today, making them identified and described as social beings. Individuals in their purchasing patterns and decisions are 
highly influenced by the interrelationships they maintain or perceive with the outer society. Thus, consumers in general, rely highly upon the ideas, views and opinions of the social environment they associate with and gain satisfaction consciously or unconsciously through choices made in such manner. (Sages \& Grable, 2008) further clarifying this situation suggest that incorporation of social norms and interpersonal considerations are considered as the forebear of behavioural intentions. Consumers, especially based in the Asian continent is well-known to have collectivist behaviour where social influence in buying decision making is more prominently seen and discussed (Kongsompong, et al., 2009).

This significant impact of interpersonal influence in product decision making is raised as a theoretically tested concept as consumer conformity behaviour. People try to follow the direction of others and abide with what significant others, falling into different valued referent groups in the society accepts and follows. During these engagements and decisions of consumers they show restraining behaviour to go against the community groups showing the importance they put on social influence in their product decisionmaking process. This self-restraint behaviour in everyday interactions manifested by qualities of obedience, self-discipline and politeness gives rise to the concept conformity (Schwartz, 1992).
Conformity, in general, is identified as the tendency of group members to establish group norms and the tendency of individuals to comply with respective group norms, susceptibility to group influence and behavioural changes in consumption behaviour (Lascu \& Zinkhan, 1999). The consumer tends to succumb to the subjective norms (Schiffman, et al., 2010) and alters his behaviour according to the social identity he wants to form of himself which could be either higher or lower depending on the product or service, mind-set and the social background.

With the evolutionary expansions of the new digital world the consumer buying behaviour is highly discussed in relation to these online platforms where consumers no more need a 'marketplace' and fulfils all their needs from a 'market space'. In this digitalized world, the internet enables a massive number of individuals worldwide to exchange information, experiences and ideas at anytime, anywhere (Rothaermel \& Sugiyama, 2001). This gives rise to virtual communities where people electronically communicate with each other while Social Networking Sites (SNS) play an important and major part of these virtual community communications. In a study conducted by Elhadidi in 2018, the research suggests that the high interactivity rates on Facebook and Twitter could be attributed to their ability to host discussions and controversies about things and events, to share information, and to internalize social values and identity (Elhadidi, 2018). 
Demonstrating the impact of this digitalized $21^{\text {st }}$ century, Sri Lanka records to have a 6.7 Million active social media user base from the total population of 21 Million, and among this portion, the majority belongs to the Colombo district, the western province of Sri Lanka (Social Media Stats Sri Lanka, 2020). Among other social networking platforms, Facebook claims to have the opportunity to satisfy all instrumental, ritualized and social interaction motives due to its characteristics that are sometimes unavailable in other social media platforms (Elhadidi, 2018).

The internet and social media usage when explored in a global context or even on a national ground many findings (Census and Statistics, 2019) highlight a special fact that age group of 25 to 34 years are the most active and engaging group in social media. According to the Department of Census and Statistics, people belonging to this age group records a $40.9 \%$ internet usage rate (Census and Statistics, 2019). This age group can generally be identified as the 'Millennials' as named by authors Strauss and Howe in 1987, as the high school graduating class of the millennium (Ikram, et al., 2019). As another finding of (Socialbakers.com, 2013), a study concerning Greece also found that among 4 Million Facebook users in the country the largest number of users fall into the age group of 25-34 years (Giota \& Kleftaras, 2013).

With the emergence of businesses and industry expansions via social networking sites fashion industry seems as one such lucrative and live industry in Sri Lanka. Studies on the retail fashion-wear industry posit fashion retailing sector takes a larger portion (39\%) which shows great possibilities towards further future growth. In the study conducted by Park in 2017, states that marketers have reported that current fashion consumers are inspired by other consumers' fashion styling shared on SNS and much more influenced by online influencers than commercial models (Park, 2017). And the researchers further identify that social needs have a higher potential to influence consumers in their shopping preferences presenting opportunities for businesses (Pentina, et al., 2008). Social groups influence the information need, purchase evaluation process and interests for fashion brands unlike the situation few years ago. The HubSpot report reveals that $71 \%$ of the consumers are more likely to make a purchase based on referrals (Ewing, 2012).

The lapses in the available literature in terms of clearly deriving influential factors and key aspects of such factors driving conformity behaviour at an considerable phase, made it worthwhile for the researcher to investigate factors influencing the consumer conformity behaviour in SNS specially on Gen Y with respect to the retail fashion industry forming its research questions as follows attending to examine the significance in e-WOM, FoMO, Sense of Belongingness, Community expertise and Public Self-consciousness on Gen Y consumer conformity behaviour. 
1.To what extent e-WOM affect Gen $Y$ consumers' conformity behaviour in social networking sites?

2.To what extent Fear of Missing Out (FoMO) affect Gen Y consumers' conformity behaviour in social networking sites?

3.To what extent Sense of Belongingness affect Gen Y consumers' conformity behaviour in social networking sites?

4.To what extent Community Expertise affect Gen Y consumers' conformity behaviour in social networking sites?

5.To what extent Public Selfconsciousness affect Gen Y consumers' conformity behaviour in social networking sites?

The consumer conformity as a research area that has practical importance in the current marketing context has not been thoroughly examined in the Sri Lankan perspective of it. Thus, the researcher's main objective is to investigate the effect of factors emerged from past literature on the Gen Y consumer conformity in Sri Lanka. The empirical investigation into discovering the background and effect of consumer conformity resulted in portraying important findings. The scholars (Westbrook, 1987; Rahman \& Mannan, 2018; Park \& Lee, 2008; Carmicheal, 2020) identified that e-WOM has a significant influence on consumers to show conformity behaviour in SNS. Further, (Przybylski et al., 2013; Wegmann et al., 2017; Kang et al., 2019 highlights FoMo as a factor that consumers show a willingness to comply with group norms and conform with their social environment. The scholarly articles on the subject also identify as same as FoMo the Sense of Belongingness consumers expect through their interpersonal connections could also lead to having conformatory product choices (Witt, 1969; Park \& Feinberg, 2010). Literature survey performed reflected insights from Community's expertise as drivers of consumer conformity behaviour at instances where they are rich in believablity and trustworthiness (Wood \& Lynch, 2002; Kelman, 1961). Findings and the available relationships on these factors discussed compelled the researcher to develop the research model as shown below to test the effect of the factors emerged from past literature on the consumer conformity in the Generation Y in Sri Lanka.

Factors affecting Gen Y

Consumer Conformity Behaviour

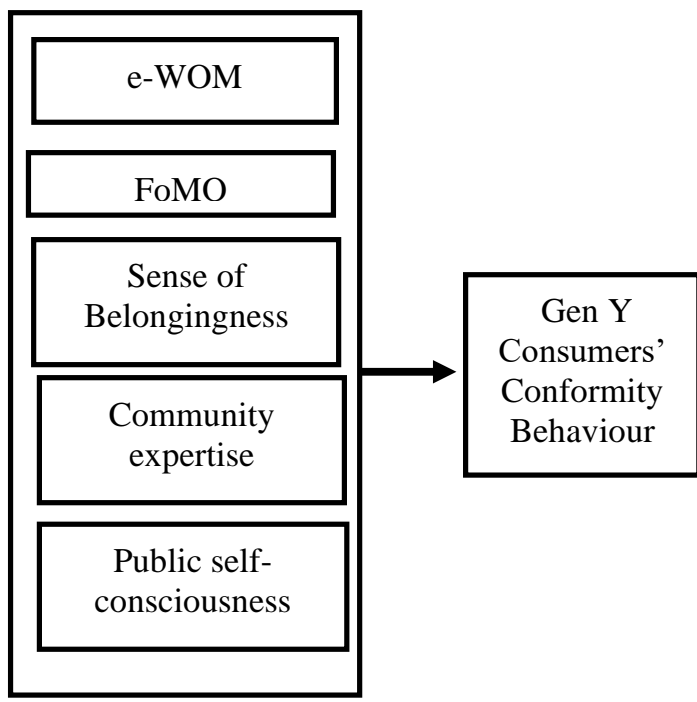

Figure 1: Conceptual framework 
Based on the framework and empirical findings presented by literature review, the following five hypotheses were developed to address the research problem.

H1: e-WOM has a significant effect on Gen Y consumers' conformity behaviour in social networking sites.

H2: Fear of Missing Out (FoMO) has a significant effect on the Gen $\mathrm{Y}$ consumers' conformity behaviour in social networking sites.

H3: Sense of Belongingness has a significant effect on the Gen Y consumers' conformity behaviour in social networking sites.

H4: Community Expertise has a significant effect on Gen Y consumers' conformity behaviour in social networking sites.

H5: Public self-consciousness has a significant effect on Gen Y consumers' conformity behaviour in social networking sites.

\section{METHODS}

The research was carried out in the deductive approach employing survey strategy. The study was performed as a cross-sectional study where the unit of analysis was individuals who are Gen Y Facebook users. Determinants of Gen Y Consumer conformity behaviour denoted the independent variables where Consumer conformity was considered to be the dependent variable. Based on the presented conceptual framework, five determinants of consumer conformity behaviour were tested (figure 1). The target population of the exploratory study were the Gen Y population i.e. people born between 1984 and 1995 (RetailWire, 2019) Facebook users in Sri Lanka. The researcher has selected the sample size as 250 in total that comprises of Colombo district Generation Y Facebook users that falls to different income ranges; the mechanism provided by Green was applied to derive the appropriate sample size (Green, 1991).

The variables and indicators relevant to the Gen Y consumers' conformity behaviour in social networking sites on retail fashion industry operationalized for the purpose of the study and a structured questionnairebased survey was conducted to collect the required information from the respondents. The instrument consisted of 32 items representing demographic information, social media usage information and the five constructs e-WOM (Ismagilova, et al., 2019), FoMO (Wegmann , et al., 2017), Sense of Belongingness (Park \& Feinberg, 2010), Community expertise (Piumali \& Rathnayake, 2017) and Public Self-consciousness (Millan \& Mittal, 2017). Responses were ranked based on a seven-point Likert scale where 1- "Strongly disagree", 2- "Disagree", 3- "More or less disagree", 4- "“Neutral", 5"More or less agree", 6- "Agree" and 7 denotes "Strongly agree". 214 valid questionnaires $(85.6 \%$ response rate) were used for data analysis. Further, descriptive statistical tools were used to analyse the data collected and the inferential statistical tools were used in testing the hypotheses of the study. 


\section{RESULTS}

The data analysis performed resulted in an analysing the demographic information on the sample. As per data derived the majority of the Generation Y respondents in the sample were females who belonged to the age group of 25 to 29 years. Further, majority of the respondents were diploma/ degree holders who were employed in the private sector at the initial stage of earnings.

The social media usage behaviour and choices as analysed in the study depicted that most of the Gen Y respondents prefer Facebook and Instagram as social networking sites, and majority of them have been members on these social media platforms for more than five years having some experience regarding online fashion purchases.

The results of the regression analysis performed to test the hypotheses are illustrated as shown below.

Table 1: Regression analysis - model significance

\begin{tabular}{|l|c|c|c|c|}
\hline \multicolumn{1}{|c|}{ Model } & $\begin{array}{c}\text { Sum of } \\
\text { Squares }\end{array}$ & df & F & Sig. \\
\hline Regression & 27.721 & 5 & 60.530 & $.000^{\mathrm{b}}$ \\
\hline Residual & 19.052 & 208 & & \\
\hline Total & 46.773 & 213 & & \\
\hline
\end{tabular}

Source: Survey results

Table 2: Regression analysis coefficients

\begin{tabular}{|c|c|c|c|}
\hline \multirow{2}{*}{ Model } & $\begin{array}{c}\text { Standardized } \\
\text { Coefficient }\end{array}$ & $\mathbf{t}$ & Sig. \\
\cline { 2 - 4 } & $\mathbf{B}$ & & \\
\hline (Constant) & & 7.462 & .000 \\
\hline e-WOM & .273 & 4.210 & .000 \\
\hline FoMO & .019 & .329 & .742 \\
\hline
\end{tabular}

\begin{tabular}{|c|c|c|c|}
\hline $\begin{array}{c}\text { Sense of } \\
\text { Belongingness }\end{array}$ & .097 & 1.608 & .109 \\
\hline $\begin{array}{c}\text { Community } \\
\text { Expertise }\end{array}$ & .389 & 5.926 & .000 \\
\hline $\begin{array}{c}\text { Public Self- } \\
\text { consciousness }\end{array}$ & .128 & 2.049 & .042 \\
\hline
\end{tabular}

Source: Survey results

The associations between independent and dependent variables were measured through the correlation test conducted.

Table 3: Correlation analysis

\begin{tabular}{|c|c|c|c|c|c|c|}
\hline Variable & CC & $\begin{array}{c}\text { e- } \\
\text { WOM }\end{array}$ & FoMO & SB & CE & PSC \\
\hline CC & 1 & $.663^{* *}$ & $.452^{* *}$ & $.527^{* *}$ & $.709^{* *}$ & $.596^{* *}$ \\
\hline
\end{tabular}

** significant at 0.05 level

Consumer Conformity (CC), Sense of Belongingness (SB), Community Expertise (CE), Public Selfconsciousness (PSC)

Source: Survey results

The hypothesis testing results upon regression analysis was as shown below in table 4 .

Table 4: Summary of hypothesis test

\begin{tabular}{|l|c|c|c|}
\hline \multicolumn{1}{|c|}{ Hypothesis } & $\begin{array}{c}\text { Beta } \\
\text { value }\end{array}$ & $\begin{array}{c}\text { Sig } \\
\text { Value }\end{array}$ & Decision \\
\hline H1: e-WOM & 0.273 & $\mathbf{0 . 0 0 0}$ & Supported \\
\hline H2: FoMO & 0.017 & 0.742 & $\begin{array}{c}\text { Not } \\
\text { Supported }\end{array}$ \\
\hline $\begin{array}{l}\text { H3: Sense of } \\
\text { belongingness }\end{array}$ & 0.083 & 0.109 & $\begin{array}{c}\text { Not } \\
\text { Supported }\end{array}$ \\
\hline $\begin{array}{l}\text { H4: } \\
\text { Community } \\
\text { expertise }\end{array}$ & 0.389 & $\mathbf{0 . 0 0 0}$ & Supported \\
\hline $\begin{array}{l}\text { H5: Public } \\
\text { self- } \\
\text { consciousness }\end{array}$ & 0.128 & $\mathbf{0 . 0 4 2}$ & Supported \\
\hline
\end{tabular}

Source: Survey results 


\section{DISCUSSION}

Reliability and internal consistency of data were measured and illustrated using Cronbach's Alpha (Cronbach,1951; Santos, 1999), where all five independent variables having an Alpha value greater than 0.7 assured having higher effective internal consistency. The validity of the data set was ensured by the Pearson's Product Moment Value test and all 'rxy' values stating the relationship between each independent and dependent variable recorded values greater than Pearson's Product Moment value (Odom \& Morrow, 2006).

A slight view of the sample was further emphasized in the descriptive analysis. It was evident that Community expertise as an independent variable has the highest mean of 5.65 while FoMO accounted as having the lowest mean of 5.23. However, all independent variables have a mean score greater than 5 and approaching 6 which denotes 'Agree' in the seven-point Likert scale used. Moreover, the standard deviation values for all independent variables has a value less than $01 \quad(\mathrm{SD}<1)$ implying all answers are relatively identical and distributed closer to the mean.

Table 5: Descriptive statistics

\begin{tabular}{|l|l|}
\hline \multicolumn{1}{|c|}{ Variable } & Mean \\
\hline Consumer Conformity & 5.7352 \\
\hline e-WOM & 5.6273 \\
\hline FoMO & 5.2395 \\
\hline Sense of Belongingness & 5.4007 \\
\hline Community Expertise & 5.6565 \\
\hline Public Self-consciousness & 5.4124 \\
\hline
\end{tabular}

Source: Survey results
As prerequisites of the regression analysis normality of the data distribution was tested using Skewness and Kurtosis indexes (Hair , et al., 2010; Byrne, 2010), where the dependent variable tends to satisfy normality requirements. Further the preliminary assumptions of the parametric statistical tools such as Homoscedasticity and Autocorrelation were tested. The results of the Breusch Pagan test assumed the data is free from heteroscedasticity issues, while Durbin Watson values obtained for all five independent variables of the study and the overall model suggested that data had no autocorrelation problems.

To identify the nature of relationship between independent and dependent variables researcher performed Correlation analysis. As presented in table 3, the correlation coefficient of e-WOM, FoMo, Sense of Belongingness, Community Expertise and Public Self-consciousness were $0.663,0.452,0.527,0.709$ and 0.596 respectively, delineating that all five variables possess statistically significant associations with Gen Y consumer conformity behaviour.

Simple regression analysis was performed in order to illustrate the impact of each independent variable with the dependent variable consumer conformity behaviour in SNS.

Regression analysis was conducted to test the research hypotheses formulated and the generated result is presented in table 2 To check the multicollinearity, the study estimated the Variance Inflation Factor which ranges well below the critical value 
10 where multicollinearity was not present.

The explanatory power $\left(\mathrm{R}^{2}\right)$ of the model was $59.3 \%$. Accordingly, $59.3 \%$ of the influential factors on consumer conformity is developed by the model developed. Based on the results only e-WOM, Community expertise and Public Selfconsciousness were significant at 0.05 level and posited significant positive effect on the dependent variable consumer conformity behaviour. Thus, alternative hypotheses formed with regards to these three independent variables were accepted. However, FoMO and Sense of Belongingness as independent variables have been statistically insignificant in the Sri Lankan context when explaining consumer conformity; hence the alternative hypothesis for the two independent variables was rejected as per model results. The hypothesis testing results as a summary is illustrated in table 4.

The findings of the statistical analysis matched with few previous literatures. In the study of (Park \& Feinberg, 2010) Sense of belongingness and Community expertise were statistically significant in explaining consumer conformity in virtual worlds. Further in the study of (Piumali \& Rathnayake, 2017) as the only other study that explored conformity behaviour in the Sri Lankan context, Sense of Belongingness and e-WOM and Community Expertise was identified having a positive impact on consumer conformity. However, in the current study, the alternative hypothesis on
Sense of Belongingness was rejected on the Gen Y consumers' context in SNS in the fashion industry. Further comparing previous findings, Public Self-consciousness was also accepted as having significant relation with the socio-cultural influence in conformity form in the studies of (Tussyadiah, et al., 2015; Zhou, et al., 2008) as same in the current study. Additionally, it was that FoMO in the current study's context is incapable of explaining Gen Y consumers' conformity behaviour in SNS in the selected context. However, FoMO was accepted as a significant variable in the study of (Kang, et al., 2019) in creating susceptible behaviour among consumers.

\section{CONCLUSION}

The study aimed at exploring the factors influencing the Gen Y consumer conformity behaviour in SNS with respect to the retail fashion industry in the context of Western province, Sri Lanka. The study results ended up concluding that e-WOM, Community expertise and Public Self-consciousness are determinants of Gen Y consumer conformity behaviour in SNS pertaining to the retail fashion industry involvement in Sri Lanka as proved by the multiple regression analysis.

The findings carry important theoretical implications in clarifying and explaining the concept of consumer conformity in the constructed new model with relation to the most involved and discussed generational cohort Gen Y. The study generates empirical evidence for confirming three Consumer 
conformity variables of e-WOM, Community expertise and Public Self-consciousness. Further, this study fills the gap of consumer conformity studies for Gen $\mathrm{Y}$ in the Sri Lankan context with the retail fashion industry. The practical implications of the study highlight the necessity of encouraging and creating positive -WOM and concentrating more on promoting and managing reviews. Further, it was recommended to improve trustworthiness and argument quality through the transparency of information shared in virtual communities.

Moreover, by customizing communication messages to improve self-presentation and recognition was suggested as boosting consumer engagement with fashion brands backed by a conforming mindset. The principal limitation of the study was the inability to access sound empirical evidence on the subject area, which might have caused in poor research arguments. In addition, the study suffered from limitation in focusing only on the fashion industry and the chance for consumers to have changing perceptions on the subject which could have affect results. However, the study provides a stepping ground for future research in consumer conformity in the Sri Lankan context with an industry overview taken. It is recommended to conduct studies with extended research models beyond the proposed research model supported by more advanced research techniques and statistical analyses.

\section{REFERENCES}

Byrne, B. M., 2010. Structural equation modeling with AMOS: Basic concepts, applications and programming. p. 396 p.

Carmicheal, K., 2020. How Online Word-of-Mouth marketing has evolved in 2020, Cambride,United States: Hubspot.

Census and Statistics, 2019. Department of Census and Statistics. [Online] Available at: http://www.statistics.gov.lk/ [Accessed 5 January 2020].

Elhadidi, A., 2018. Beyond Access to Social Media: A Comparison of Gratifications, Interactivity and Content Usage among Egyptian Adults. Global Media Journal, pp. 16-30.

Ewing, M., 2012. 71\% More Likely to Purchase on Social Media Referrals, Cambridge, United States: HubSpot Blogs.

Giota, K. \& Kleftaras, G., 2013. The Role of Personality and Depression in problamatic use of Social Networking Sites in Greece. Journal of Psychological Research on Cyberspace, 7(3).

Green, S. B., 1991. How Many Subjects Does It Take To Do A Regression Analysis. Multivariate Behavioral Research, 26(3), pp. 499-510.

Hair, J. F., Black, W. C., Babin, B. J. \& Anderson , R. E., 2010. 
Multivariate Data Analysis: A Global Perspective.

Ikram, S., Tajbhoy, M. A., Hassanally Sarah \& Perera, S., 2019. The Fallacy of Marketing to Millennials: Why Sri Lanakan Marketers Should Discard Generational Labels. Colombo Business Journal, 10(02).

Ismagilova, E., Slade, E., Rana, N. \& Dwivedi, Y., 2019. The effect of Electronic word-of-mouth communications on intention to buy: A Meta-Analysis. Information Systems Frontiers.

Kang, I., Cui, H. \& Son, J., 2019. Conformity consumption behavior and FoMo. Sustainability, 11(17), pp. 118.

Kelman, H. C., 1961. Process of Opinion Change. Public Opinion Quarterly, 25(1), pp. 57-78.

Kongsompong, K., Patterson , P. \& Green , R., 2009. Collectivism and social influence in the buying decision: A four country study of inter and intra national differences. Australian Marketing Journal, 17(3), pp. 142-149.

Lascu, D. \& Zinkhan, G., 1999. Consumer conformity: Review and applications for marketing theory and practice. Journal of marketing theory and practice, 7(3), pp. 1-12.

Martinez-Ruiz, M. P. \& Moser, K. S., 2019. Studying consumer behaviour in an online context:
The impact of the evolution of the World Wide Web for new avenues in research. Frontiers in Psychology.

Millan, E. \& Mittal, B., 2017. Consumer preference for status symbolism of clothing: The case of the Czech Republic. Psychology and Marketing, 34(3), pp. 309-322.

Odom, L. R. \& Morrow, J. R., 2006. What's this r? A Correlational Approach to Explaining Validity, Reliability and Objectivity Coefficients. Measurement in Physical Education and Exercise Science, 10(2), pp. 137-145.

Park , J. \& Feinberg, R., 2010. Eformity: Consumer conformity behaviour in virtual communities. Journal of research in interactive marketing, pp. 197-213.

Park, D.-H. \& Lee, J., 2008. eWOM overload and its effect on consumer behavioral intention depending on consumer involvement. Electronic Commerce Research and Application, 7(4), pp. 386-398.

Park, H., 2017. How social media is transforming fashion consumers: The effects of'social consumer" attributes on brand engagement in social networking sites. Fashion, Industry and Education, 15(1), pp. 1-11.

Park, Y. \& Feinberg, R., 2010. EFormity: Consumer conformity behavior in virtual 
communities. Journal of Research in Interactive Marketing, 4(3), pp. 197-213.

Pentina, I., Prybutok, V. \& Zhang, X., 2008. The roleof virtual communiites as Shopping Reference Groups. Journal of Electronic Commerce Research, Volume 9.

Piumali, P. \& Rathnayake, D., 2017. Factors affecting consumer conformity behavior in virual communities: with special reference to Generation $\mathrm{Y}$ in Sri Lanka. SEUSL Journal of Marketing, 2(2).

Przybylski, A., Murayama, K., DeHaan , C. \& Gladwell, V., 2013. Motivational, emotioanl and behavioral correlates of fear of missing out. Computing Human Behavior, Volume 29, pp. 1841-1848.

Rahman, M. \& Mannan, M., 2018. Consumer online purchase behavior of local fashion clothing brands: A study on Information Adoption, eWOM, Online brand familiarity, and Online Brand Experience. Journal of Fashion Marketing and Management: An International Journal, 22(3), pp. 404-419.

RetailWire, 2019. RetailWire. [Online]

Available at:

https://retailwire.com/discussio n/nearly-half-of-onlinefashion-shoppers-say-socialmedia-inspired-their-lastpurchase/

[Accessed 5 January 2020].
Rothaermel, F. \& Sugiyama, S., 2001. Virtual Internet communities and commercial success: Individual and community lvel theory grounded in the attypical case of TimeZone.com. Volume 27, pp. 297-312.

Sages, R. A. \& Grable, J. E., 2008. A test of the theory of SelfEsteem-A consumer behavior perspective.

Schiffman, L., Kanuk, L. \& Wisenblit, J., 2010. Consumer behavior. 10th Edition ed. Upper Saddle River: NJ Pearson Education.

Schiffman, L., Kanuk, L. \& Wisenblit, J., 2010. Consumer behaviour. 10th Edition ed. Upper Saddle River: NJ Pearson Education.

Schwartz, S. H., 1992. Universals in the Content and Structure of values: Theoretical Advances and Empirical Tests in 20 countries. Volume 25, pp. 1-65.

Social Media Stats Sri Lanka, 2020. Global Stats-Statcounter. [Online]

Available at: https://gs.statcounter.com/socia 1-media-stats/all/sri-lanka [Accessed 5 January 2020].

Socialbakers.com, 2013. Greece Facebook Statistics.[Online] Available at: https://www.socialbakers.com/ statistics/facebook/pages/total/ greece?orderBy $=$ penetration 
Tussyadiah, I., Kausar, D. \& Soesilo, P., 2015. The Effect of Engagement in Online Social Network on Susceptability to Influence. Journal of Hospitality and Tourism Research, pp. 1-23.

Wegmann, E., Oberset, U., Stodt, B. \& Brand, M., 2017. OnlineSpecific fear of missing out and Internet use expectancies contribute to symptoms Internet communication disorder, s.1.: s.n.

Westbrook, $\quad 1987$. Product/Consumption-based affective responses and postpurchase processes. Journal of marketing research, 24(3), pp. 258-270.

Witt, R., 1969. Informal Social Group Influenceon consumer brand Choice. Journal of Marketing Research, 7(4), pp. 533-535.

Wood, S. L. \& Lynch, J. G., 2002. Prior Knowledge and Complacency in New Product Learning. Journal of Consumer Research, 29(3), pp. 416-426.

Zhou, L., Teng, L. \& Poon, P., 2008. Susceptability to Global Consumer Culture: A threedimensional scale. Psychology and Marketing, Volume 25, pp. 336-351. 